\title{
Exploring Role Efficacy as correlate to Organizational Citizenship Behaviour among Female Nurses in a Maternal and Childcare Facility
}

\author{
Naga Siddharth* and Rupal Agarwal ${ }^{\dagger}$
}

\section{Abstract}

\begin{abstract}
While many studies on Organizational Citizenship Behaviour exist, role efficacy as a correlate to organisational citizenship behaviour offers potential for research. This study is conducted to explore Role Efficacy as a correlate of Organizational Citizenship Behaviour among female nurses in a maternity and child care hospital in the healthcare industry located at Bangalore in India. Role Efficacy is the potential effectiveness of an individual occupying a particular position in an organization, as perceived by the individual. The convenience sample included 31 nurses and supervisors from an organization that caters exclusively to maternity
\end{abstract}

* Chief People Officer, Cloudnine, India; siddharthn@cloudninecare.com naga@nagasiddharth.com

† Junior Manager - HR, GMR Ltd, India; rupal.agarwal.90@gmail.com

\section{Acknowledgement}

The authors are grateful to their families for the journey of life. The authors also acknowledge their mentors and teachers for their patience and generosity; to the management and staff of Cloudnine for allowing the conduct of the study, and in particular Mr Rohit M.A. for instantly approving it, Ms Sherryl McGregor and Ms Ruth Patterson for working the schedules of the staff to accommodate the study. 
and childcare. Pareek's (2002) instrument on Role Efficacy was used for measuring OCB. Those items related to dimensions of Courtesy, Sportsmanship and Civic behaviour were adapted from as cited in Aykler, (2011) and those on Helping and Conscientiousness were adapted from MacKenzie, Podsakoff \& Fetter, (1993) and used in a questionnaire responded to by the supervisors of the nursing staff. The findings indicate that role efficacy is positively correlated to Organizational Citizenship Behaviour, but not significantly. Correlations of dimensions of role efficacy to Organizational Citizenship Behaviour are also reported to have useful implications on managerial action and for performance design experts. Positive correlation between Influence and OCB dimensions of Civic behaviour and conscientiousness were reported.

Keywords: Organization citizenship behaviour, Healthcare, Role efficacy, Extra role behaviour, Nurses

"What are the things you would like your employees to do more of, but really can't make them do, and for which you can't guarantee any definite rewards, other than your appreciation?" (Smith, Organ and Near 1983, cited in Organ, Podsakoff, MacKenzie 2006, p.16)

\section{Introduction}

India's health sector is at the threshold of large scale corporatization and exponential growth in 2012. India has 0.9 beds per 1000 people as against the global average of 3.3, requiring 100,000 additional hospital beds each year, at investment of approximately INR 45,000 to INR 50,000 crore per year for the next 10 years. Moreover, there is a shortfall of 1.4 million doctors and 2.8 million nurses in India. Worthy of note is that healthcare personnel will need to prepare and reorient themselves to more informed and evolved customers. (Gearing up for Healthcare 3.0, McKinsey \& Company, 2010). This places both employees and organisations at a stage where employees are looking for roles where they can be effective and organisations desire Organization Citizenship Behaviours (referred to as OCB in this paper) from employees. In this context, it is of interest to the authors to study whether there exists a positive linkage between Role efficacy and OCB among 
nurses in a maternal and child care facility located at Bangalore in India.

\section{Organizational Citizenship Behaviour}

Organisational citizenship behaviour (OCB) as a concept is now almost 25 years old. However, in the current hypercompetitive business environment, where organisations are looking for anything which can help them achieve competitive advantage, OCB may well provide the answer. OCB can be traced to Organ's (1977) 'A Reappraisal and Reinterpretation of the SatisfactionCauses-Performance Hypothesis'. The roots of the construct could be traced back to Barnard (1938), and Katz (1964), as cited by Saradha \& Patrick (2011). OCB is defined as, 'individual behaviour that is discretionary, not directly or explicitly recognized by the formal reward system, and that in the aggregate promotes the effective functioning of the organization' (Organ, 1988). Organ (1997) refined this definition, conceptualizing 'organizational citizenship behaviour as any form of performance that supports the social or psychological environment in which the work tasks are embedded.' Organizational Citizenship Behaviours (OCBs) are a special type of work behaviours that are defined as individual behaviour that promotes the goals of the organization by contributing to its social and psychological environment (Organ, 1997; Rotundo \& Sackett, 2002). Some of these behaviours include voluntarily helping peers, taking personal initiatives for the development of the team, volunteering innovation; not wasting time and performing extra duties without complaint. These behaviours are believed to be instrumental for the effective functioning of the organization (Organ, 1983).

Organ (1988) differentiated five facets or factors: altruism, courtesy, conscientiousness, civic virtue, and sportsmanship. Altruism (e.g. helping Behaviours directed at specific individuals). In a health care organization, such Behaviours can help the medical staff (doctors, nurses, paramedical) in working towards the common organizational goals. Conscientiousness (e.g. going beyond minimally required levels of attendance), Conscientiousness behaviour of medical staff viz: doctors, nurses, paramedical staff would make them to avoid casual talks or spending lengthy time 
on personal telephone conversation and make them sure to attend patients on time and perform their duties as required. Sportsmanship (e.g. tolerating the inevitable inconveniences of work without complaining). Inculcation of sportsmanship behaviour among medical employee enables them to avoid finding faults and avoid blowing problems out of proportion within or outside the medical department and improves the amount of time spent on constructive endeavours in the organization. Courtesy (e.g. informing others to prevent the occurrence of work related problems) Assessing and doing what is best for the patients as well as for the employees will help in strengthening courtesy dimension. Civic Virtue (e.g. participating in and being concerned about the life of the company). Organ (1990) also included two additional factors: peacekeeping and cheerleading.

Williams and Anderson (1991) proposed a two-dimensional conceptualization to Organ's (1988) conceptualization of OCB: OCB-I (Behaviour directed towards individuals; comprising altruism and courtesy) and OCB-II (Behaviour directed towards organization, comprising the remaining three dimensions i.e. conscientiousness, sportsmanship and civic virtue.

\section{Dimensions of OCB}

Research on OCB has benefitted greatly from Organ's (1988) conceptualization of OCB that consists of five distinct factors: Altruism (e.g. helping behaviours directed at specific individuals), Conscientiousness (e.g. going beyond minimally required levels of attendance), Sportsmanship (e.g. tolerating the inevitable inconveniences of work without complaining), Courtesy (e.g. informing others to prevent the occurrence of work-related problems), and Civic Virtue (e.g. participating in and being concerned about the life of the company).

The proposed model by Organ could find support for a three factor model of OCB. In this recent conceptualization, Conscientiousness is removed and Altruism and Courtesy are combined to form a single helping dimension (Podsakoff \& MacKenzie, 1994), resulting in three factors (i.e. Helping Behaviour, Civic Virtue, and Sportsmanship). However a recent meta-analysis conducted by Hoffman, Blair, Meriac, and Woehr (2007) suggested that "current 
operationalizations of OCB are best viewed as indicators of a general OCB factor and holistic approach is better than the compartmentalization of the concept. (as cited in Srivastava \& Saldanha, 2008). For the purpose of this study, the authors chose to go with five dimensions of OCB considering the large number of studies that exist which consider five dimensions rather than three or seven dimensions, thus allowing the present study to be compared with for further research.

\section{Difference between OCB and ERB}

Extra Role Behaviour, as opposed to in-role behaviour, is per definition a behaviour that tries to benefit the organization and that "goes beyond existing role requirements." (Organ, Podsakoff, MacKenzie, 2006) Failing to perform the required in-role behaviour (Katz 1964, cited in Van Dyne and Le Pine 1998, p.108), will have financial consequences and bear the risk of losing the job, while extra-role behaviour is discretionary. Extra role behaviour is: "(1) not specified in advance by role prescriptions, (2) not recognized by formal reward systems and (3) not a source of punitive consequences when not performed by job incumbents." (Van Dyne and Le Pine 1998). There are some similarities between the ERB dimension of "helping" and some OCB behaviours especially the "altruism" dimension. Nevertheless the definition of ERB tends to exclude those types of $O C B$ which are not explicitly beyond role requirements, but fit into the definition of $O C B$ as soon as the level of engagement in a certain behaviour, such as "compliance", exceeds the minimum standards required by the job description. (Organ, Podsakoff and MacKenzie 2006) Both the antecedents and the immediate consequences of OCB and ERB are quite different. (Organ, Podsakoff, MacKenzie, 2006)

\section{Select Indian studies on OCB}

Studies in India measuring OCB and their outcomes are briefly reviwed:

Bhatnagar \& Sandhu, (2005), who studied 111 managers of the IT sector organizations in India indicated that managers who perceive psychological empowerment in their occupational environment exhibit organisational citizenship behaviour. Chaitanya \& Tripathi, 
(2001), in a study of 100 scientific officers of a public sector organisation in southern India reported Altruism, Sportsmanship and Perception of organization towards OCB significantly predicted Organization commitment. Bhargava \& Rupashree, (2009) in their study identify core self-evaluations, family support, supervisor support and job characteristics as the antecedents of work-to-family enrichment and family satisfaction, job satisfaction, affective commitment and organizational citizenship behaviour (OCB) as its outcomes. Singh \& Singh, (2009) studied correlations between OCB and personality. Singh \& Srivastava, (2009) investigated the relationship between certain individual level determinants of interpersonal trust and its impact on organizational citizenship behaviour. Krishnan \& Arora (2008), looked at the relationships between leader's organizational citizenship behaviour (OCB), transformational leadership, and follower's OCB. Sardha \& Harold, (2011) in their study examined the relationship between Employee Engagement and OCB. Gunavathy \& Indumati, (2011) in their study aimed at understanding the relationship between various demographic variables and leadership that an employee experiences from his supervisor and Organization Citizenship Behaviour. Sharma, Bajpai \& Holani, (2011) looked at the difference in the degree of Organization Citizenship Behaviour present in the employees of public and private sector organisations. A study in India in the healthcare sector presents an opportunity to research OCB. OCB studies have been conducted among nurses in Malaysia. Harif, (2005) in his study undertook to examine the factors that influence organizational citizenship behaviour in an organization. These factors included procedural justice, distributive justice, job satisfaction and commitment as the theoretical model proposed that job satisfaction has an effect on OCB through affective commitment.

\section{Role Efficacy}

The performance of a person working in an organisation can be thought of as depending on his competencies and his own potential effectiveness in the role as well as the design of his role that he is expected to perform. Just as personal efficacy is the potential 
effectiveness of the person, role efficacy is the potential effectiveness of an individual in his/her role as perceived by the individual. (Pareek, 1987) Dimensions of role efficacy are 3 in number (Pareek, 1987).

Dimension 1: Role Making has four sub dimensions, Self-role integration (the degree to which the individual's strengths are allowed to be used by the role), Proactivity (possibility of the individual being allowed in his/her role to take initiative in starting something new), Creativity (an opportunity to be creative and to try out newer and unconventional ways of solving problems is important in a role) and Confrontation (tendency to confront problems and find relevant solutions contributes to efficacy)

Dimension 2: Role Centring has three sub dimensions, Centrality (feeling that the role occupied is central to the Organisation increases role efficacy), Influence (the possibility of the role holder influencing others around him/her) and Personal growth (the role providing the individual with an opportunity to grow and develop)

Dimension 3: Role Linking has three sub dimensions, Inter-role linkage (possibility of joint effort to solve problems results in higher role efficacy), Helping relationship (possibility of the role holder receiving help when needed increases role efficacy) and Superordination (when the role holder perceives that what he does is of value to a larger cause or a group)

\section{Select literature review on Role efficacy}

Role theory was first identified in the 1930s, but it was not until years later (Katz \& Kahn, 1978) that role theory became more widely recognized and readily used in organizational research (Harris, 2004). This is supported by Biddle (1986) asserting that, "Role theory is a science concerned with the study of behaviours that are characteristic of persons within contexts and with various processes that presumably produce, explain, or are affected by those behaviours". Role theory explains roles as individuals having social positions and hence having expectations for the behaviours of themselves and others. In addition, the theory suggests that the sender's role will affect the role of a receiver, which will later affect the role of the sender, and so on (Harris, 2004). 
Saxena, (2009) referred to the studies of Sen (1982-83), and Sayeed (1992) on role efficacy: Surti \& Sen (1982-1983) indicated that persons with role efficacy experience less role stress and also they effectively cope up with the behaviours. Sen's study on role efficacy has found out that Role efficacy has high positive correlation with internal locus of control. Sayeed (1992) in his study on role efficacy found out that there is a strong linkage between appropriate power position structure and role efficacy.

Nair referred to studies that indicated that Role Efficacy was found to be related to the quality of work life measured by influence, amenities at the work place, nature of job and supervisory behaviour. Pandey, (1995) revealed role efficacy and role stress to be negatively related. The studies suggested that similar mechanisms are involved in sustaining both volunteerism and OCB. (as cited in Srivastava \& Saldanha, 2008)

\section{Hypothesis development}

Rao (1985) defines HRD as "a process by which the employees of an organisation are helped in a continuous planned way, to: acquire or sharpen capabilities required to perform various functions associated with their present or expected future roles; develop their general capabilities as individuals, and discover and exploit their inner potential for their own and/or organisational development purposes; develop an organisational culture in which the supervisor-subordinate relationships, teamwork, and collaboration among sub-units are strong and contribute to the professional well being, motivation and pride of employees." Developing Role Efficacy has been referred to as one of the interventions of Human Resources Development. (Acharya \& Siddharth, 2007). The authors explore whether Role efficacy has a positive significant effect as a correlate to OCB and arrive at the hypothesis for this study being H1: There is a significant positive relationship between Role Efficacy and Organizational citizenship Behaviour 


\section{Methodology}

This study was exploratory and was conducted among the employees of an organization in the field of healthcare, that catered exclusively to maternity and child care. The organization was situated at Bangalore in India. Data was obtained through primary research. The technique adopted for the purpose of the research was convenience sampling technique. A total of 31 female nursing staff participated in the process which included both the nurses as well as the supervisors. The questionnaire method was adopted to collect data. Two questionnaires were administered, one to the nursing staff and the other to the supervisors.

Role Efficacy Scale developed by Pareek, (2002) was responded to by the nurses.

Organizational citizenship Behaviour items were responded to by the supervisors. Of these items, those related to dimensions of Courtesy, Sportsmanship and Civic behaviour were adapted from as cited in Aykler, (2011) and those on Helping (referred to as Altruism in this study) and Conscientiousness were adapted from MacKenzie, Podsakoff \& Fetter (1993). Minor changes of her for his/her and nursing/nurses were made. For each of the employees, this was responded to by their immediate supervisors.

\section{Results}

Table 1: Indicating Mean and SD for the five dimensions of $\mathrm{OCB}$

\begin{tabular}{|l|l|l|}
\hline & Mean & $\begin{array}{c}\text { Std. } \\
\text { Deviation }\end{array}$ \\
\hline Courtesy & 16.00 & 2.556 \\
\hline Altruism & 11.26 & 1.843 \\
\hline Sportsmanship & 25.97 & 5.003 \\
\hline Civic & 10.65 & 2.244 \\
\hline Conscientiousness & 11.87 & 1.607 \\
\hline OCB & 75.74 & 9.338 \\
\hline
\end{tabular}

The highest scores were observed in Sportsmanship, followed by Courtesy. 
The table below indicates the descriptive statistics for the ten dimensions of Role Efficacy, the total of the ten sub dimensions and the Role Efficacy Index computed as per Pareek, (2002).

Table 2: Indicating the Mean and SD for the 10 dimensions of Role Efficacy

\begin{tabular}{|l|l|l|}
\hline Centrality & \multicolumn{1}{|c|}{ Mean } & \multicolumn{1}{|c|}{$\begin{array}{c}\text { Std. } \\
\text { Deviation }\end{array}$} \\
\hline Integration & 3.90 & .870 \\
\hline Proactivity & 1.94 & 1.207 \\
\hline Creativity & 3.10 & .870 \\
\hline Rlink & 3.42 & 1.025 \\
\hline Hlprel & 2.45 & 1.710 \\
\hline Superordination & 2.48 & 1.458 \\
\hline Influence & 2.45 & .810 \\
\hline Growth & 3.32 & .871 \\
\hline Confrontation & 3.55 & .675 \\
\hline
\end{tabular}

The highest scores were observed in the Confrontation, Integration and Role linkage, in that order. The lowest observed is Proactivity followed by helping relationship and Superordination.

H1: There is a significant positive relationship between Role Efficacy and Organizational citizenship Behaviour 
Table 3: Correlation between dimensions of Role Efficacy and OCB *Correlation is significant at the 0.05 level (1-tailed)

\begin{tabular}{|c|c|c|c|c|c|c|c|}
\hline \multicolumn{8}{|c|}{ Correlations } \\
\hline & & 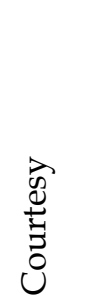 & 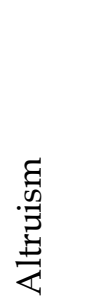 & 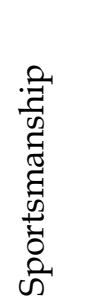 & $\sum_{0}^{u}$ & 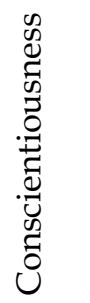 & $\ddot{0}$ \\
\hline \multirow{3}{*}{ Centrality } & $\begin{array}{l}\text { Pearson } \\
\text { Correlation }\end{array}$ & 0.015 & 0.162 & $\begin{array}{c}- \\
0.169\end{array}$ & .0 .155 & $\begin{array}{c}- \\
0.057 \\
\end{array}$ & $\begin{array}{c}- \\
0.102 \\
\end{array}$ \\
\hline & $\begin{array}{l}\text { Sig. } \\
\text { (1-tailed) }\end{array}$ & 0.468 & 0.193 & 0.181 & 0.203 & 0.381 & 0.293 \\
\hline & $\mathrm{N}$ & 31 & 31 & 31 & 31 & 31 & 31 \\
\hline \multirow{3}{*}{ Integration } & $\begin{array}{l}\text { Pearson } \\
\text { Correlation }\end{array}$ &. & $\begin{array}{c}- \\
0.069 \\
\end{array}$ & 0.102 & 0.098 & 0.117 & $\begin{array}{c}- \\
0.001 \\
\end{array}$ \\
\hline & $\begin{array}{l}\text { Sig. } \\
\text { (1-tailed) }\end{array}$ & 0.043 & 0.356 & 0.293 & 0.3 & 0.265 & 0.498 \\
\hline & $\mathrm{N}$ & 31 & 31 & 31 & 31 & 31 & 31 \\
\hline \multirow{3}{*}{ Proactively } & $\begin{array}{l}\text { Pearson } \\
\text { Correlation }\end{array}$ & -0.02 & 0.145 & $\begin{array}{c}- \\
0.127\end{array}$ & 0.15 & 0.296 & 0.042 \\
\hline & $\begin{array}{l}\text { Sig. } \\
\text { (1-tailed) }\end{array}$ & 0.458 & 0.219 & 0.248 & 0.21 & 0.053 & 0.411 \\
\hline & $\mathrm{N}$ & 31 & 31 & 31 & 31 & 31 & 31 \\
\hline \multirow{3}{*}{ Creativity } & $\begin{array}{l}\text { Pearson } \\
\text { Correlation }\end{array}$ & 0.105 & 0.129 & $\begin{array}{c}- \\
0.045\end{array}$ & 0.069 & 0.128 & 0.069 \\
\hline & $\begin{array}{l}\text { Sig. } \\
\text { (1-tailed) }\end{array}$ & 0.287 & 0.244 & 0.405 & 0.355 & 0.246 & 0.356 \\
\hline & $\mathrm{N}$ & 31 & 31 & 31 & 31 & 31 & 31 \\
\hline \multirow{3}{*}{ Rlink } & $\begin{array}{l}\text { Pearson } \\
\text { Correlation }\end{array}$ & 0 & 0.064 & $\begin{array}{c}- \\
0.205 \\
\end{array}$ & 0.096 & $\begin{array}{c}- \\
0.067 \\
\end{array}$ & $\begin{array}{c}- \\
0.086 \\
\end{array}$ \\
\hline & $\begin{array}{l}\text { Sig. } \\
\text { (1-tailed) }\end{array}$ & 0.5 & 0.366 & 0.134 & 0.304 & 0.36 & 0.323 \\
\hline & $\mathrm{N}$ & 31 & 31 & 31 & 31 & 31 & 31 \\
\hline
\end{tabular}




\begin{tabular}{|c|c|c|c|c|c|c|c|}
\hline \multicolumn{8}{|c|}{ Correlations } \\
\hline & & 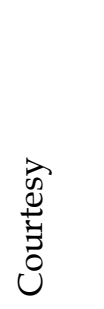 & 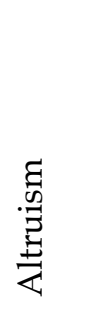 & 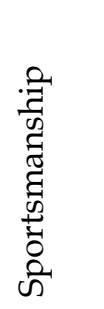 & $\sum_{0}^{\frac{u}{2}}$ & 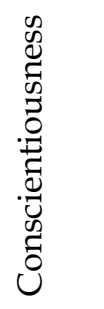 & טै \\
\hline \multirow{3}{*}{ Hlprel } & $\begin{array}{l}\text { Pearson } \\
\text { Correlation }\end{array}$ & 0.252 & $\begin{array}{c}- \\
0.006\end{array}$ & 0.197 & $\begin{array}{c}- \\
0.044\end{array}$ & $\begin{array}{c}- \\
0.112\end{array}$ & 0.143 \\
\hline & $\begin{array}{l}\text { Sig. } \\
\text { (1-tailed) }\end{array}$ & 0.086 & 0.486 & 0.145 & 0.408 & 0.275 & 0.221 \\
\hline & $\mathrm{N}$ & 31 & 31 & 31 & 31 & 31 & 31 \\
\hline \multirow{3}{*}{$\begin{array}{l}\text { Super } \\
\text { ordination }\end{array}$} & $\begin{array}{l}\text { Pearson } \\
\text { Correlation }\end{array}$ & 0 & 0.25 & $\begin{array}{c}- \\
0.062 \\
\end{array}$ & 0.156 & 0.084 & 0.068 \\
\hline & $\begin{array}{l}\text { Sig. } \\
\text { (1-tailed) }\end{array}$ & 0.5 & 0.088 & 0.371 & 0.201 & 0.326 & 0.358 \\
\hline & $\mathrm{N}$ & 31 & 31 & 31 & 31 & 31 & 31 \\
\hline \multirow{3}{*}{ Influence } & $\begin{array}{l}\text { Pearson } \\
\text { Correlation }\end{array}$ & 0.225 & 0.299 & 0.275 & $.366^{*}$ & $.328^{*}$ & $.413^{*}$ \\
\hline & $\begin{array}{l}\text { Sig. } \\
\text { (1-tailed) }\end{array}$ & 0.111 & 0.051 & 0.067 & 0.021 & 0.036 & 0.011 \\
\hline & $\mathrm{N}$ & 31 & 31 & 31 & 31 & 31 & 31 \\
\hline \multirow{3}{*}{ Growth } & $\begin{array}{l}\text { Pearson } \\
\text { Correlation }\end{array}$ & 0.225 & 0.154 & $\overline{-}$ & 0.231 & 0.197 & 0.109 \\
\hline & $\begin{array}{l}\text { Sig. } \\
\text { (1-tailed) }\end{array}$ & 0.112 & 0.204 & 0.234 & 0.106 & 0.144 & 0.28 \\
\hline & $\mathrm{N}$ & 31 & 31 & 31 & 31 & 31 & 31 \\
\hline \multirow{3}{*}{ Confrontation } & $\begin{array}{l}\text { Pearson } \\
\text { Correlation }\end{array}$ & 0.039 & 0.07 & $\begin{array}{c}- \\
.370^{*}\end{array}$ & $\begin{array}{c}- \\
0.197\end{array}$ & 0.006 & -0.22 \\
\hline & $\begin{array}{l}\text { Sig. } \\
\text { (1-tailed) }\end{array}$ & 0.418 & 0.354 & 0.02 & 0.144 & 0.487 & 0.117 \\
\hline & $\mathrm{N}$ & 31 & 31 & 31 & 31 & 31 & 31 \\
\hline
\end{tabular}

\section{Discussion of results}

The correlation between Role Efficacy Index (REI) and overall OCB is positive, but not significant when tested using a one-tailed test. Hypothesis $\mathrm{H} 1$ stands rejected. 
However, there are a few correlations that the authors discuss since these have interesting implications.

Integration and Courtesy are significantly negatively correlated. This could be due to the nature of the role being perceived as primarily being of a technical nature and of an individual contributor, rather than one that is linked to the organization.

Confrontation and sportsmanship are significantly negatively correlated. This could possibly be attributed to the fact that the supervisors who provided feedback could have viewed confrontation of issues as non-sportsmanship behaviours.

Influence is significantly positively correlated to Civic behaviours. This could possibly imply that those who perceive their roles as allowing them to influence, tend to exhibit civic behaviours since those behaviours could stand a chance of achieving change through influence.

Influence is also significantly positively correlated to Conscientiousness. This could possibly imply that those who perceive their roles as allowing them to influence, tend to exhibit behaviours of Conscientiousness (which could be through their coworkers observing them).

According to Bhakshi., et.al., (2011), demographic variables show no significant impact on the Organizational citizenship behaviour. Alotaibi (2001) also found that none of the demographic variables such as age and gender correlated with OCB. Schappe's (1998) also found no significant correlation between age, gender and OCB.

Among the demographic variables collected, Courtesy was significantly negatively co-related with age. This is possibly due to India's culture being high in Power-Distance as discussed by Hofstede (2011). Also, Civic virtue behaviours were significantly positively co-related to experience.

\section{Implications of the study}

According to Schyns, the supervisor often has the discretion to offer valuable job assignments to employees; these provide a potential for enactive attainment, or actual success experiences. Pellegrini and Scandura (2006) and Schyns et al. (2005) found that 
leaders are more likely to provide beneficial delegation opportunities to workers with whom they have a high quality Leader Member Exchange (LMX) relationship. This may also provide effective learning opportunities for workers (Walumbwa et al., 2009).

With a few dimensions of Role Efficacy indicating that they have a significant positive correlation with a few dimensions of OCB in this study, it becomes worthwhile to consider whether supervisors can be trained to increase the role efficacy of subordinates and thus also have an additional positive impact on the organization through OCB of subordinates. This might mean upskilling supervisors in areas of coaching employees and helping employees perceive aspects of their role's potential that they might not be aware of.

\section{Limitations of the Study}

The current study has the following limitations. First, the data for research was collected from one organisation in Bangalore and hence, the findings cannot be generalized to the Healthcare Industry in India. Second, the research employed convenience sampling to accomplish research objectives. For further research, simple random sampling is recommended to be used in order to increase the generalizability of the findings of the research. Third, the research focussed only on female nurses in the organisation.

\section{Suggestions for future research}

The authors suggest that future research in this sector is carried out to study gender variations, generalizability across India and also explore any variations if a scale developed for OCB in India is used.

\section{Conclusion}

Service based organizations, such as Healthcare, require individuals with high role efficacy. Research suggests that several studies on OCB have highlighted the relationship between OCB and Role Clarity, Role Conflict and Role Ambiguity. Role Conflict and Role Ambiguity are negatively related to Role Efficacy and also to Organizational Citizenship Behaviour. However, in globally 
published literature, there is no research to find out the relationship that exists between Role Efficacy and Organizational Citizenship Behaviour in the Healthcare Industry in India.

As per Todd, (2003), OCB can be affected by instilling in employees a perception of expertise in their job tasks, employees with higher role efficacy show growth orientation, attitudinal commitment, positive and approach behaviour. They also tend to feel more satisfied with life, with their jobs and organizational role in general (Surti and Sen, 1982-1983).

From this exploratory study, the authors are happy to note that Influence as a sub-dimension of Role Efficacy has positive correlation on two dimensions of OCB, namely, Civic behaviour and conscientiousness. This is a useful insight for managers and performance design experts. Improving the perception of influence that an employee holds in a role can improve two dimensions of OCB-something money cannot buy!

\section{References}

Acharya, V. U., Siddharth, N., (2007), A Business HR intervention using the concept of organizational roles experience sharing and exploratory findings, Kaustubham, TISS

Ahmadi, A. A. S., Ahmadi, F., Tavreh, N., (2011), The relationship between organizational citizenship behaviour and burnout in public organization in West Azarbayejan province, Interdisciplinary Journal of Contemporary Research in Business, 2 (11)147-156

Allameh, S. M., Amiri, S., Asadi, A., (2011) A Survey of relationship between organizational commitments and organizational citizenship behaviour case study: Regional water organization of Mazandaran province, Interdisciplinary Journal of Contemporary Research in Business, 3 (5).

Aykler, J., (2010), The influence of personality factors on organizational citizenship behaviour, BADWW Institute for change management and management development

Bakshi. A., Sharma. A. D., (2011), Organizational commitment as predictor of organizational citizenship behaviour, European Journal of Business and Management, 3 (4).

Benjamin, A., (2012), Human resource development climate as a predictor of citizenship behaviour and voluntary turnover intentions in the banking sector, International Business Research, 5 (1). 
Bhargava, S., Baral, R., (2009), Antecedents and consequences of workfamily enrichment among Indian mangers, Psychological Studies, 54, 213-225.

Bhatnagar, J., Sandhu, S., (2005), Psychological empowerment and organisational citizenship behaviour (OCB) in 'IT' managers: A talent retention tool, Indian Journal of Industrial Relations, 40(4).

Biswas, M. (2010), Vilakshan: The XIMB Journal of Management 7, (1).

Chahal, H., Mehta, S. (2011), Antecedents and consequences of organisational citizenship behaviour (OCB): A conceptual framework in reference to health care sector., Journal of Services Research, 11(1).

Chaitanya, S. K., Tripathi, N., (2001), Dimensions of organisational citizenship behaviour, Indian Journal of Industrial Relations, 37(2).

Chin. S. T. S., Anantharaman, R. N., David, Y. K. T., (2011), Emotional intelligence and organisational citizenship behaviour of manufacturing sector employees: An analysis, Management 6(2) 107125.

Gunavathy, J. S., Indumathi, G., (2011), Leadership and organization citizenship behaviour-A study among employees of a civil engineering company, BVIMR Management Edge, 4(1).

Harif, A. R., (2005), A test of the relationships among perceptions of justice, job satisfaction, affective commitment and organizational citizenship behaviour, Gadjah Mada International Journal of Business, 7, (2).

Hofstede, G., (2011), Dimensionalizing cultures: The Hofstede model in context. Online readings in psychology and culture 2(1). Retrieved from http://scholarworks.gvsu.edu/orpc/vol2/iss1/8/.

Hyde, A. M., Pethe, S., (2005), Impact of HRD climate on empowerment and organization citizenship behaviour, The IUP Journal of Organizational Behaviour.

Ibrahim, A. B., (2010), A correlation study of leader-member exchange and organizational citizenship behaviour in a public sector organization, Journal of Global Business \& Economics, 1 (1).

Khalid, S. A., (2009), Organizational citizenship behaviour factor structure among employees in hotel industry, International Journal of Psychological Studies, 1(1).

Krishnan, V. R., Arora, P., (2008), Determinants of transformational leadership and organizational citizenship behaviour, Asia-Pacific Business Review, IV( 1).

Kumar, K., Bakhshi, A., (2009), Organizational citizenship behaviour in India: Development of a scale, International Journal of Organisational Behaviour, 14(1). 
Lathalavanya, B., Thenmozhi, R., (2011), Organizational citizenship behaviour evaluating organizational efficiency and success through knowledge sharing, Journal of Contemporary Management Research, 5 (1).

MacKenzie, Scott B., Podsakoff. P. M., Fetter, R., (1993), The impact of organizational citizenship behaviour on evaluations of salesperson performance, Journal of Marketing, 57(1).

Mohammad, J., Habib, Farzana Q. B., Alias, M Adnan Bin, (2010), Organizational justice and organizational citizenship behaviour in higher education institution,. Global Business $\mathcal{E}$ Management Research, 2(1).

Nair, S. K., (n.d.). A study of role stress and role efficacy among indian women executives. International Journal of Arts and Science, 2(5).

Najari, R., Ahmadi, F., Habibitabar, Z., (2011), Study of relationship between personality and organizational citizenship behaviour (OCB) in public organizations in Iran., Interdisciplinary Journal of Contemporary Research in Business, 3(2).

Organ, D. W., Podsakoff, P. M., MacKenzie, S. B., (2006): Organizational Citizenship Behaviour. It's nature, antecedents and consequences. Thousand Oaks, California: Sage.

Pandey, A., (1995), "Role efficacy and role stress relationship : some experience with workers". Indian Journal of Industrial Relations, 31(2).

Pareek, U., (2002), Training instruments in HRD and OD. Tata McGraw-Hill Publications

Peng, J., Chiu, S., (2010), An integrative model linking feedback environment and organizational citizenship behaviour, Journal of Social Psychology, 150(6)

Podsakoff, P. M., Ahearne, M., MacKenzie, S. B., (1997), Organizational citizenship behaviour and the quantity and quality of work group performance. Journal of Applied Psychology, 82.

Rotundo, M., \& Sackett, P. R. (2002). The relative importance of task, citizenship, and counterproductive performance to global ratings of job performance: A policy capturing approach. Journal of Applied Psychology, 87(1), 66-80.

Salvati, A., Batmani, F., Ahmadi, F., Faraji, B., (2011), The role of personality in development of organizational citizenship behaviour, Interdisciplinary Journal of Contemporary Research in Business, 3 (3).

Saradha, H., Patrick, H. A.,(2011), Employee engagement in relation to organizational citizenship behaviour in information technology organization, Journal of Marketing \& Management, 2 (2).

Saxena, D. (2009). Actualizing Managerial Roles Through Corporate Leadership: Exploring Indian Corporates ( $\left.1^{\text {st }} \mathrm{ed}\right)$. New Delhi: University Science Press. 
Sharma, J. P., Bajpai, N., Holani, U., (2011), organizational citizenship behaviour in public and private sector and its impact on job satisfaction: A comparative study in Indian perspective. International Journal of Business \& Management, 6(1).

Singh, A. K., Singh, A. P., (2009), Does personality predict organisational citizenship behaviour among managerial personnel, Journal of the Indian Academy of Applied Psychology, 35.

Singh, S. K., Organ, D. W., Podsakoff, P. M., et.al, (2007), Organizational citizenship behaviour: its nature, antecedents, and consequences, IIMB Management Review, 19(2).

Singh, Upasana and Srivastava.K.B.L., (2009), Interpersonal trust and organizational citizenship behaviour, Psychological Studies, 54.

Srivastava K., Saldanha D., (2008), Organizational citizenship behaviour. Indian Psychiatry Journal, 17(1) 1-3

Sutton, M. J., (2005), Organizational citizenship behaviour: A career development strategy, Scholar Commons Graduate Theses and Dissertations Paper 880 . Retrieved from http:// scholarcommons.usf.edu/etd/880,http://www.psychit.com.au/Psychlopedia/article.asp?id=272

Walumbwa. F. O, Cropanzano, R. \& Goldman. B. M., (2011), How leadermember exchange influences effective work behaviours: Social exchange and internal-external efficacy perspectives, Personnel Psychology, 64(3).

Wei, Y., Yani, Z., (2010), Analysis on the influence of supervisory role on staffs' organizational citizenship behaviours in service enterprises. Shandong Univ. of Finance, Jinan, China, Information and Financial Engineering (ICIFE), 2nd IEEE International Conference Papers 426429 